\title{
BIOLOGY OF AGEING
}

\begin{abstract}
SYMPOSIUM on the biology of ageing wis held by the Institute of Biology at University College, London, during September 27-28. Papers covered a wide and heterogeneous field, the first day being devoted to the biological and cytological, and the second to the psychological, industrial, nutritional and genetic aspects of age processes.

Sir Cyril Hinshelwood (University of Oxford) described the changes which characterize the decline of cells in non-proliferating bacterial cultures. Studies of the exchange of radioisotopes between nondividing cells and the medium suggest that the reversal of synthetic enzyme activities which takes place under these conditions is accompanied by active synthesis elsewhere in the system; but this re-utilization of the labelled materials is incomplete, and there is a steady leakage of activity into the medium. The near-random decline of such a cell population, which is a possible source of analogy with the behaviour of populations of post-mitotic tissue cells, may be due to the coincidence of a number of periodicities, the death of any one non-dividing cell occurring when several cyclical processes of resynthesis happen to reach a minimum simultaneously.

Dr. O. V. S. Heath (Imperial College, London) dealt with the mechanism of the growth check which accompanies the flowering of some higher plants, and with sequential changes in the composition and shape of leaves produced by meristems, as examples of two age changes in the life-cycle of plants. He described experiments suggesting that the change-over from growth to reproduction, which produces marked checking in most plants, and is fatal in annuals, is not wholly a nutritional effect.
\end{abstract}

Dr. A. Comfort (University College, London) described the importance of vertebrate vital stat. istics in the study of the phylogeny and com. parative physiology of animal ageing. Actuarial senescence has been studied in laboratory populations of guppies (Lebistes reticulatus) under experimental conditions. Survival curves of a great many non-domestic vertebrates tend to approach an arithmetic straight line, the number of deaths being constant in unit time. Some advance has recently been made in compiling life-tables for zoo animals; but among laboratory mammals they are available only for rats and mice, and search is being made for analysable records to indicate age-mortality relations in birds, marsupials and poikilotherms. Important now information of this kind is being obtained by Prof. F. Bourlière (Faculty of Modicine, Paris), whose paper was presented in his absence, and by his collaborators working on the growth and fertility of vertebrates in the wild, both by means of ringing studies and through the use of techniques of ageing reptiles by inspection-the French workers are particularly concerned with the effects upon the lifespan of metabolic factors such as those due to hibernation and climate, and are attempting to compare the longevities of populations in warm and cold latitudes.

Dr. G. H. Bourne (London Hospital) described striking differences in enzyme distribution, revealed by histochemical methods, between tissue cells of young and old rats, with a gross increase in the alkaline phosphatase, particularly of the Purkinje cells, but also in liver, kidney and elsewhere. These changes are not confined to cells the life of which is equal to that of the animal but occurs also in the 'young' cells of old animals. Dr. G. I. M. Swyer (University College Hospital) gave an account of the progress recently made by a number of workers in describing the changes in output of individual steroid hormones with the advance of age in man. Of the $\alpha$-ketosteroids, the 11-deoxy fraction decreases most regularly with age in both sexes, the 11-oxy-17-keto fraction less, and the 11-oxyetiocholanones least. Although human ageing is quite certainly not a simple consequence of steroid deficiency, the separation of these differently reacting components has already opened the possibility of more effective replacement therapy in the treatment of some consequences of senility.

Dr. H. M. Sinclair (University of Oxford) discussed two nutritional factors in the timing of human senescence-the effects of rapid growth in childhood and of overfeeding in the adult upon length of life, and the possibility that the arterial diseases of human old age are direct or indirect consequences of a deficiency of unsaturated fatty acids due to changes in dietary habits over the past century. Ho described experiments suggesting that not only the total intake but also the isomeric structure of unsaturated fatty acids in the diet are important determinants of atherosclerosis, and that the requirement of these substances is much higher in men than in women.

Dr. J. Maynard Smith (University College, London) gave an account of genetical research on the relation of longevity to vigour. Although there is a correlation between parental and child longevity, this is much smaller than the sib-sib correlation, and only one-quarter that for stature between parent and child. In laboratory stocks, heterozygosity appears to be the most important single correlate of long lifo, which is part of the general complex of vigour found in hybrids.

Other papers dealt with the demographic aspects of ageing (Dr. B. Benjamin, Office of the RegistrarGeneral), the functional changes with age in man and their effects on employability (Prof. W. Hobson, University of Leeds), the use of the working life in man and animals as a measure of ageing (F. le Gros Clark) and the psychological changes occurring with age in man (Dr. A. Heron, Medical Research Council Occupational Research Unit, University of Liverpool). The papers and subsequent discussion are to be published later.

\section{FEEDING LABORATORY ANIMALS}

$T$ HE nutrition of laboratory animals was the subject of a symposium, organized jointly by the Nutrition Society and the Laboratory Animals Bureau, and held at Guy's Hospital Medical School, London, on October 6. It was the 105th meeting of the Nutrition Society and the fifth in the series of Laboratory Animals Bureau symposia. Dr. S. K. Kon (National Institute for Research in Dairying) was in the chair, and nine papers were presented. 